\title{
Immunonutrition in gastrointestinal surgery
}

\author{
Y. Cerantola, M. Hübner, F. Grass, N. Demartines and M. Schäfer \\ Department of Visceral Surgery, University Hospital Vaudois (CHUV), Bugnon 46, 1011 Lausanne, Switzerland \\ Correspondence to: Professor N. Demartines (e-mail: Demartines@chuv.ch)
}

\begin{abstract}
Background: Patients undergoing major gastrointestinal surgery are at increased risk of developing complications. The use of immunonutrition (IN) in such patients is not widespread because the available data are heterogeneous, and some show contradictory results with regard to complications, mortality and length of hospital stay.

Methods: Randomized controlled trials (RCTs) published between January 1985 and September 2009 that assessed the clinical impact of perioperative enteral IN in major gastrointestinal elective surgery were included in a meta-analysis.

Results: Twenty-one RCTs enrolling a total of 2730 patients were included in the meta-analysis. Twelve were considered as high-quality studies. The included studies showed significant heterogeneity with respect to patients, control groups, timing and duration of IN, which limited group analysis. IN significantly reduced overall complications when used before surgery (odds ratio (OR) 0.48, 95 per cent confidence interval (c.i.) 0.34 to 0.69 ), both before and after operation (OR $0.39,0.28$ to 0.54 ) or after surgery (OR 0.46, 0.25 to 0.84 ). For these three timings of IN administration, ORs of postoperative infection were $0.36(0.24$ to 0.56$), 0.41(0.28$ to 0.58$)$ and $0.53(0.40$ to 0.71$)$ respectively. Use of IN led to a shorter hospital stay: mean difference -2.12 (95 per cent c.i. -2.97 to $-1 \cdot 26)$ days. Beneficial effects of IN were confirmed when low-quality trials were excluded. Perioperative IN had no influence on mortality (OR $0.90,0.46$ to 1.76 ).

Conclusion: Perioperative enteral IN decreases morbidity and hospital stay but not mortality after major gastrointestinal surgery; its routine use can be recommended.
\end{abstract}

Paper accepted 26 July 2010

Published online 7 October 2010 in Wiley Online Library (www.bjs.co.uk). DOI: 10.1002/bjs.7273

\section{Introduction}

Patients undergoing major gastrointestinal surgery, such as cancer surgery, are at increased risk of developing complications, although surgical techniques and perioperative care have improved in recent years. Postoperative complications decrease quality of life, prolong hospital stay and may delay adjuvant oncological treatment. Furthermore, use of healthcare resources and costs are related to the extent of postoperative morbidity ${ }^{1-3}$.

Pre-existing malnutrition and the patient's stress response to surgical trauma are among the most important factors that have a negative impact on outcome ${ }^{1,3-6}$. On the other hand, there is increasing evidence that optimized nutritional support may decrease the number of adverse events after major gastrointestinal surgery ${ }^{1,7-9}$. To improve nutritional status, various nutritional formulas have been tested, using different routines of access and administration schedules, for use in daily clinical practice. With the advent of novel nutritional formulas containing agents that modulate the immune system, such as glutamine, arginine, $n-3$ fatty acids (FA) and RNA, a new era of nutritional therapy began almost two decades ago. Primarily in an experimental setting, these nutrient agents have shown beneficial effects on key features of the acute stress response ${ }^{10,11}$.

The clinical impact of immunonutrition (IN) has been evaluated in numerous studies s, $^{2,10,12-19}$. However, use of different patient groups, nutritional formulas and protocols for administration, as well as diverse control groups, has confounded the interpretation of available studies. Early reviews and meta-analyses suggested no change in mortality, but a decrease in postoperative infection rates and length of hospital stay with use of $\mathrm{IN}^{11,20,21}$. However, they are flawed by significant bias, such as data heterogeneity and inadequate control groups, and 
do not include recently published randomized controlled trials (RCTs).

The aim of this systematic review and meta-analysis was to assess the impact of IN on postoperative complications, in particular infectious complications, length of hospital stay and mortality in patients undergoing major gastrointestinal surgery. Tolerance of IN diets and costs were also evaluated.

\section{Methods}

\section{Data sources and search strategies}

Main electronic databases including MEDLINE (searched through PubMed), Embase, the Cochrane Database of Systematic Reviews and the Cochrane Central Register of Controlled Trials were searched. Medical subject heading $(\mathrm{MeSH})$ terms were used for searching PubMed. (Immunonutri $^{*}$ OR (enteral OR preoperative OR perioperative OR postoperative OR specialized OR immune enhancing) nutri* OR oral nutritional supp* OR malnutrition OR malnourished OR arginine OR glutamine OR fish oil OR omega-3 fatty acids OR nucleotides OR RNA OR Impact) AND ((general OR visceral OR abdominal OR colorectal OR hepatobiliary OR upper GI OR lower GI OR gastrointestinal OR liver OR pancreatic
OR gastric OR oesophageal) surg $^{*}$ ) AND (complications OR pneumonia OR anastom ${ }^{*}$ OR infect $\left.{ }^{*}\right)$ were entered as keywords.

In addition, electronic links to related articles and references of selected articles were hand-searched. Various trial registries (http://clinicaltrials.gov, http://clinicaltrial.org, http://isrctn.org, http://actr.org.au, http://trialregister.nl and http://www.umin.ac.jp/ctr) were screened for unpublished relevant RCTs, whose principal investigators were contacted. Finally, commercial manufacturers of IN formulas were contacted for ongoing RCTs on IN.

The search was limited to studies published between January 1985 and September 2009. IN was defined as enteral nutrition composed of at least two of the three main components: amino acids (arginine and/or glutamine), omega-3 FA ( $n-3 \mathrm{FA})$ and RNAs. The IN formulas were not available commercially before 1985 . Articles written in all languages were considered eligible. Only RCTs performed in humans were included in the analysis.

\section{Study selection}

RCTs selected for the final meta-analysis had to compare enteral IN, given either before, both before and after, or after operation, with control groups that received standard enteral nutrition. Studies comparing two different

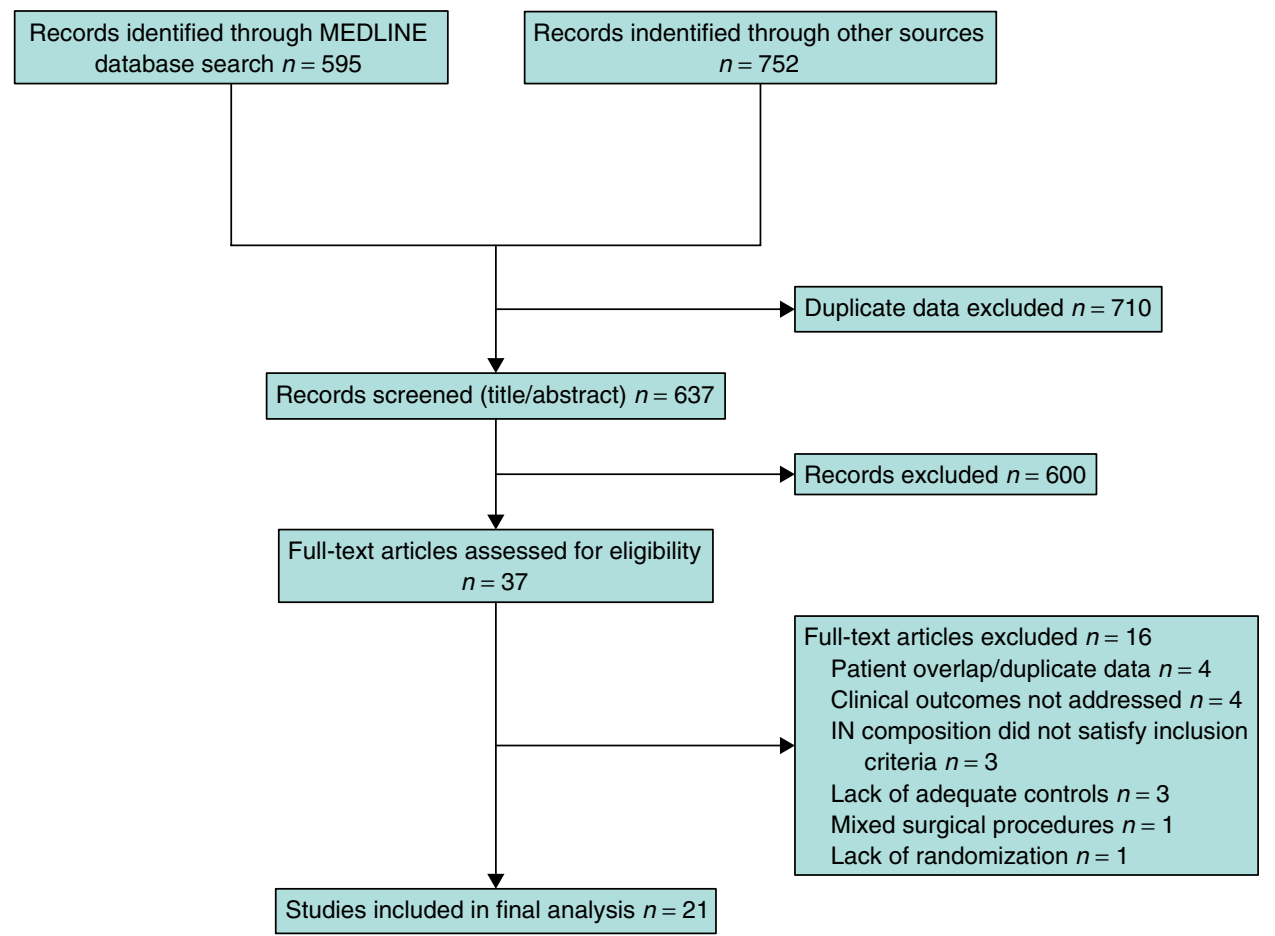

Fig. 1 Flow chart showing selection of studies for analysis. IN, immunonutrition 
regimens of IN (different IN formulas, timings and duration) but with no actual control group were excluded, as were those comparing IN with parenteral nutrition. Only RCTs considering patients undergoing elective major gastrointestinal surgery were included. Traumarelated abdominal surgery, transplantation surgery and conservative treatment of critically ill patients were considered as exclusion criteria. At least one of the following main outcome measures had to be reported: overall complications, infectious complications, in-hospital mortality and length of hospital stay.

\section{Data extraction and quality assessment}

Two authors performed the literature search independently. The search terms were first identified in the title, and then in the abstract or MeSH. All studies of interest were obtained as full-text articles and scrutinized. The entire research team made the final decision to include a study. Of note, authors of multiple studies were contacted in order to avoid inclusion of duplicate data.

Relevant data were extracted and documented in a database developed a priori for all publications. The following items were recorded for each study: authors, title, year of publication, methodological details (such as randomization process, double-blinding methods, classification of complications), patient characteristics (number of patients, prevalence of malnutrition, use of antibiotics and neoadjuvant treatment), details of the nutritional intervention (type, timing, dose, duration, route of administration), overall and infectious complications, mortality, length of hospital stay, and secondary outcome parameters such as compliance and cost.

The methodological quality and internal validity of included studies was assessed using the Jadad score ${ }^{22}$. Data are presented in accordance with the PRISMA statement ${ }^{23}$.

Table 1 Study characteristics

\begin{tabular}{|c|c|c|c|c|c|c|c|c|}
\hline \multirow[b]{2}{*}{ Reference } & \multirow[b]{2}{*}{ Year } & \multirow[b]{2}{*}{ Procedure } & \multirow{2}{*}{$\begin{array}{l}\text { No. of patients } \\
\text { randomized (groups } \\
\text { analysed) }\end{array}$} & \multirow[b]{2}{*}{ Timing } & \multirow[b]{2}{*}{ Control } & \multicolumn{3}{|c|}{ Immunonutrition } \\
\hline & & & & & & Contents & Dose $(1 / \text { day })^{\star}$ & $\begin{array}{l}\text { Preop./postop. } \\
\text { duration (days) }\end{array}$ \\
\hline Braga et al. ${ }^{12}$ & 1999 & UGI, LGI† & $206(85 / 86)$ & Periop. & $\mathrm{ICN}$ & Arg, $n-3$ FA, RNA & $\begin{array}{l}\text { Preop. } 1 \text { (oral) } \\
\text { Postop. } 1.5 \text { (FT) }\end{array}$ & $7 / 7$ \\
\hline Braga et al. ${ }^{28}$ & 2002 & UGI, LGI† & $150(50 / 50 / 50)$ & Preop., periop. & $\mathrm{ICN}$ & Arg, $n-3$ FA, RNA & $\begin{array}{l}\text { Preop. } 1 \text { (oral) } \\
\text { Postop. } 2 \text { (FT) }\end{array}$ & $7 / 7$ \\
\hline Braga et al. ${ }^{10}$ & 2002 & $\mathrm{LGl} \dagger$ & $200(50 / 50 / 50 / 50)$ & Preop., periop. & ICN, RD & Arg, $n-3$ FA, RNA & $\begin{array}{l}\text { Preop. } 1 \text { (oral) } \\
\text { Postop. } 1.5 \text { (FT) }\end{array}$ & 5/open \\
\hline Daly et al. ${ }^{13}$ & 1992 & $\mathrm{UGl} \dagger$ & $85(41 / 44)$ & Postop. & IC & Arg, $n-3 \mathrm{FA}, \mathrm{RNA}$ & $1.8(\mathrm{FT})$ & -/open \\
\hline Daly et al..$^{29}$ & 1995 & UGl† & $60(30 / 30)$ & Postop. & $\mathrm{ICN}$ & Arg, $n-3$ FA, RNA & $1.8(\mathrm{FT})$ & -/open \\
\hline Di Carlo et al. ${ }^{24}$ & 1999 & UGl† & $100(33 / 35 / 32)$ & Postop. & ICN, TPN & Arg, $n-3$ FA, RNA & $1.8(\mathrm{FT})$ & -/open \\
\hline Farreras et al. ${ }^{14}$ & 2005 & $\mathrm{UGI} \dagger$ & $66(30 / 30)$ & Postop. & $\mathrm{ICN}$ & Arg, $n-3$ FA, RNA & $1.2(\mathrm{FT})$ & $-/ 7$ \\
\hline Finco et al. ${ }^{30}$ & 2007 & LGI by LS & $28(14 / 14)$ & Periop. & $\mathrm{RD}$ & Arg, $n-3$ FA, RNA & $\begin{array}{l}\text { Preop. } 0.8 \text { (oral) } \\
\text { Postop. } 0.8 \text { (oral) }\end{array}$ & $6 / 3$ \\
\hline Gianotti et al. ${ }^{25}$ & 1997 & UGl† & $260(87 / 87 / 86)$ & Postop. & ICN, TPN & Arg, $n-3$ FA, RNA & $1.7(\mathrm{FT})$ & $-/ 7$ \\
\hline Gianotti et al. ${ }^{7}$ & 2002 & UGI, LGI $\dagger$ & $305(102 / 101 / 102)$ & Preop., periop. & $I V G+R D$ & Arg, $n-3$ FA, RNA & $\begin{array}{l}\text { Preop. } 1 \text { (oral) } \\
\text { Postop. } 1.5 \text { (FT) }\end{array}$ & 5/open \\
\hline Gunerhan et al. ${ }^{26}$ & 2009 & UGI, LGI† & $56(16 / 13 / 13)$ & Preop. & $\mathrm{IC}, \mathrm{RD} \ddagger$ & Arg, $n-3$ FA, RNA & NS & $7 /-$ \\
\hline Jiang et al. ${ }^{15}$ & 2001 & UGI, LGI† & $120(60 / 58)$ & Postop. & $\mathrm{ICN}$ & Arg, $n-3$ FA, RNA & $1.7(\mathrm{FT})$ & $-/ 10$ \\
\hline Jiang et al..$^{32}$ & 2004 & UGI, LGI & $124(60 / 60)$ & Postop. & $\mathrm{ICN}$ & Glu, $n-3$ FA & $2 \cdot 1(\mathrm{FT})$ & $-/ 7$ \\
\hline Klek et al. ${ }^{16}$ & 2008 & UGI† & $196(92 / 91)$ & Postop. & ICN & Arg, Glu, $n-3$ FA & $1.5(\mathrm{FT})$ & $-/ 7$ \\
\hline Klek et al. ${ }^{17}$ & 2008 & $\mathrm{UGl} \dagger$ & $205(52 / 53 / 51 / 49)$ & Postop. & $\mathrm{ICN}$ & Glu, n-3 FA & $1.5(\mathrm{FT})$ & $-/ 7$ \\
\hline Okamoto et al. ${ }^{31}$ & 2009 & $\mathrm{UGI} \dagger$ & $60(30 / 30)$ & Preop. & IC & Arg, $n-3$ FA, RNA & 0.8 (oral) & $7 /-$ \\
\hline Satinský et al..$^{19}$ & 2005 & UGI & $62(21 / 20 / 21)$ & Postop. & ICN, TPN $\ddagger$ & Arg, Glu, n-3 FA & $1.3(\mathrm{FT})$ & -/open \\
\hline Schilling et al. ${ }^{27}$ & 1996 & UGI, LGl $\dagger$ & $45(14 / 14 / 13)$ & Postop. & IC, IVG & Arg, $n-3$ FA, RNA & $1.3(\mathrm{FT})$ & -/open \\
\hline Senkal et al. ${ }^{18}$ & 1997 & UGI $\dagger$ & $164(77 / 77)$ & Postop. & IC & Arg, $n-3$ FA, RNA & $1.8(\mathrm{FT})$ & $-/ 5$ \\
\hline Senkal et $a l^{2}$ & 1999 & $\mathrm{UGl} \dagger$ & $178(78 / 76)$ & Periop. & IC & Arg, $n-3$ FA, RNA & $\begin{array}{l}\text { Preop. } 1 \text { (oral) } \\
\text { Postop. } 1.7 \text { (FT) }\end{array}$ & $5 / 5$ \\
\hline Xu et al..$^{33}$ & 2006 & UGI, LGI† & $60(30 / 30)$ & Preop. & ICN & Arg, $n-3$ FA, RNA & $1.8(\mathrm{FT})$ & $7 /-$ \\
\hline
\end{tabular}

*Dose 3 days after enteral nutrition was started. When data were given in kcal per kg per day, conversion was performed based on an average 70-kg patient and considering that $1 \mathrm{ml}$ of IN formula contains $1 \mathrm{kcal}(25 \mathrm{kcal}$ per $\mathrm{kg}$ per day converts to $1.75 \mathrm{l} /$ day). $\dagger$ Oncological surgery. $\ddagger$ Group not considered for meta-analysis. UGI, upper gastrointestinal surgery; LGI, lower gastrointestinal surgery; ICN, isocaloric and isonitrogenous; Arg, arginine; n-3 FA, omega-3 fatty acids (unsaturated); FT, feeding tube; RD, regular diet; IC, isocaloric; TPN, total parenteral nutrition; LS, laparoscopy; IVG, intravenous glucose solution; NS, not stated; Glu, glutamine. 


\section{Statistical analysis}

Statistical analysis was performed using Review Manager Software for Windows ${ }^{\circledR}\left(\operatorname{RevMan}^{\circledR}{ }^{\circledR}\right.$ 5.0.23; The Nordic Cochrane Centre, Copenhagen, Denmark) and Prism ${ }^{\circledR}$ 5.2 (GraphPad Software, La Jolla, California, USA).

Treatment effects were expressed as odds ratios (ORs) or mean differences, with 95 per cent confidence intervals. Heterogeneity was assessed using the $\chi^{2}$ test and $I^{2}$ test. Data across studies were pooled using fixed-effects (inverse variance) and random-effects models.

Funnel plots were drawn to visualize symmetry and asymmetry in order to evaluate possible publication bias.

\section{Results}

The electronic literature search yielded 637 studies for potential inclusion. Of these, 576 and 24 studies were excluded based on the title and abstract respectively. Thirty-seven studies were evaluated as full-text articles, of which 16 were subsequently excluded (Fig. 1). The search of the MEDLINE database using PubMed revealed all included articles; the other data sources did not provide additional studies. Overall, 21 RCTs with 2730 patients met the inclusion criteria, and were included in the metaanalysis. Nine studies involved more than two arms. In six of these $\mathrm{e}^{17,19,24-27}$, other comparative groups were not considered valid and only two arms were therefore analysed for comparison. In the remaining three multiple-arm studies comparing preoperative and perioperative $\mathrm{IN}^{7,10,28}$, the two study groups were compared with the control group, thus accounting for a total of 24 comparisons with controls in the 21 studies included (6,12 and 6 comparisons of preoperative, postoperative, and combined preoperative and postoperative IN respectively).

\section{Study characteristics}

Fifteen studies were carried out in a single centre $7,10,12,13,16$, $17,19,24-31$ and the remainder were multicentre trials $\mathrm{s}^{2,14,15}$,

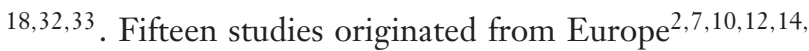
$16-19,24-28,30$, two from the USA ${ }^{13,29}$ and four from Asia $^{15,31-33}$.

Eleven studies included only patients undergoing upper gastrointestinal tract surgery ${ }^{2,13,14,16-19,24,25,29,31}$. Another eight included patients undergoing either upper or lower gastrointestinal tract surgery $7,12,15,26-28,32,33$. Two studies included primarily patients undergoing lower gastrointestinal tract surgery ${ }^{10,30}$. All except three studies ${ }^{19,30,32}$ included patients having cancer surgery (Table 1). Twenty trials included patients undergoing open

Table 2 Quality assessment of randomized controlled trials on the clinical impact of perioperative immunonutrition in major gastrointestinal surgery

\begin{tabular}{|c|c|c|c|c|c|c|c|}
\hline \multirow[b]{2}{*}{ Reference } & \multirow[b]{2}{*}{ Year } & \multirow[b]{2}{*}{ Analysis } & \multicolumn{5}{|c|}{ Jadad score } \\
\hline & & & Overall & Allocation concealment & Double-blinding & Blinding satisfactory & Withdrawals/dropouts \\
\hline Braga et al. ${ }^{12}$ & 1999 & PP & 5 & 1 & 1 & 1 & 1 \\
\hline Braga et al. ${ }^{28}$ & 2002 & ITT & 3 & 1 & 0 & 0 & 1 \\
\hline Braga et al. ${ }^{10}$ & 2002 & ITT & 3 & 1 & 0 & 0 & 1 \\
\hline Daly et al. ${ }^{13}$ & 1992 & PP & 3 & 1 & 0 & 0 & 1 \\
\hline Daly et al..$^{29}$ & 1995 & ITT & 2 & 1 & 0 & 0 & 0 \\
\hline Di Carlo et al..$^{24}$ & 1999 & ITT & 1 & 0 & 0 & 0 & 0 \\
\hline Farreras et al. ${ }^{14}$ & 2005 & PP & 5 & 1 & 1 & 1 & 1 \\
\hline Finco et al. ${ }^{30}$ & 2007 & ITT & 2 & 1 & 0 & 0 & 0 \\
\hline Gianotti et al. ${ }^{25}$ & 1997 & ITT & 1 & 0 & 0 & 0 & 0 \\
\hline Gianotti et al. ${ }^{7}$ & 2002 & ITT & 3 & 1 & 0 & 0 & 1 \\
\hline Gunerhan et al. ${ }^{26}$ & 2009 & PP & 2 & 0 & 0 & 0 & 1 \\
\hline Jiang et al. ${ }^{15}$ & 2001 & PP & 5 & 1 & 1 & 1 & 1 \\
\hline Jiang et al. ${ }^{32}$ & 2004 & PP & 1 & 0 & 0 & 0 & 0 \\
\hline Klek et al..$^{16}$ & 2008 & PP & 4 & 1 & 1 & 0 & 1 \\
\hline Klek et al. ${ }^{17}$ & 2008 & ITT & 3 & 1 & 0 & 0 & 1 \\
\hline Okamoto et al. ${ }^{31}$ & 2009 & ITT & 2 & 1 & 0 & 0 & 0 \\
\hline Satinský et al. ${ }^{19}$ & 2005 & PP & 3 & 1 & 0 & 0 & 1 \\
\hline Schilling et al. ${ }^{27}$ & 1996 & ITT & 2 & 0 & 0 & 0 & 1 \\
\hline Senkal et al. ${ }^{18}$ & 1997 & PP & 5 & 1 & 1 & 1 & 1 \\
\hline Senkal et al. ${ }^{2}$ & 1999 & PP & 3 & 0 & 1 & 0 & 1 \\
\hline Xu et al. ${ }^{33}$ & 2006 & ITT & 1 & 0 & 0 & 0 & 0 \\
\hline
\end{tabular}

The Jadad score assigns one point each for proper randomization, allocation concealment, double-blinding with adequate methodology, and listing of withdrawals and dropouts. Studies with 3 or more of a maximum of 5 points are accounted as high quality. As randomization was a sine qua non condition for inclusion, all studies had at least 1 point. The column 'randomization' is therefore not displayed. PP, per protocol; ITT, intention to treat. 
surgery and one trial included patients having gastrointestinal laparoscopy ${ }^{30}$. None of the patients with cancer received neoadjuvant chemotherapy and/or radiotherapy. Adjuvant oncological treatment was not reported, as trial endpoints were in-hospital morbidity and mortality.

IN formula with arginine, $n-3 \mathrm{FA}$ and RNA was used in 17 studies, $2,10,12-15,18,24-31,33$; four studies used formulas containing arginine, glutamine and $n-3$ $\mathrm{FA}^{16,19}$, and glutamine and $n-3 \mathrm{FA}^{17,32}$. After surgery, control groups received either isocaloric ${ }^{2,13,18,26,27,31}$ or isocaloric and isonitrogenous ${ }^{10,12,14-17,19,24,25,28,29,32,33}$ enteral nutritional formulas. In two RCTs, patients in the control group were fed with a regular oral $\operatorname{diet}^{7,30}$.

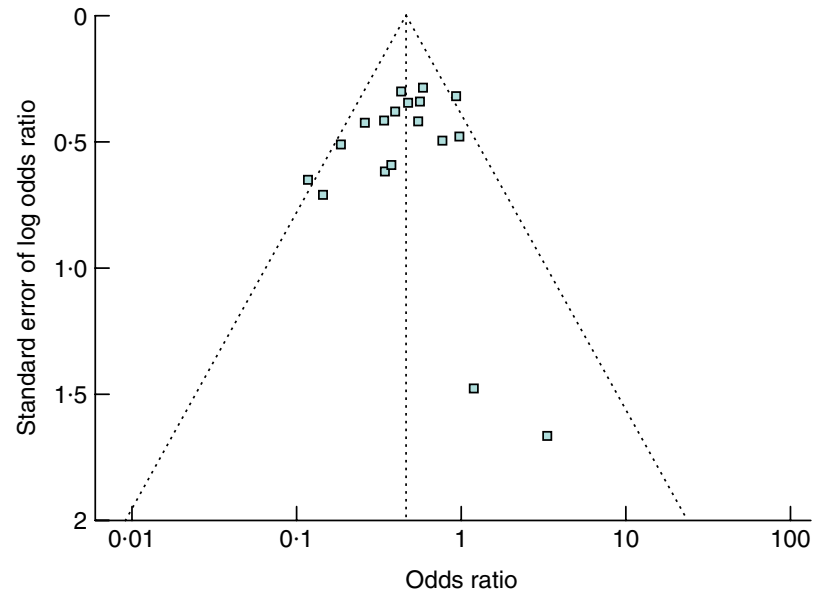

a Complications

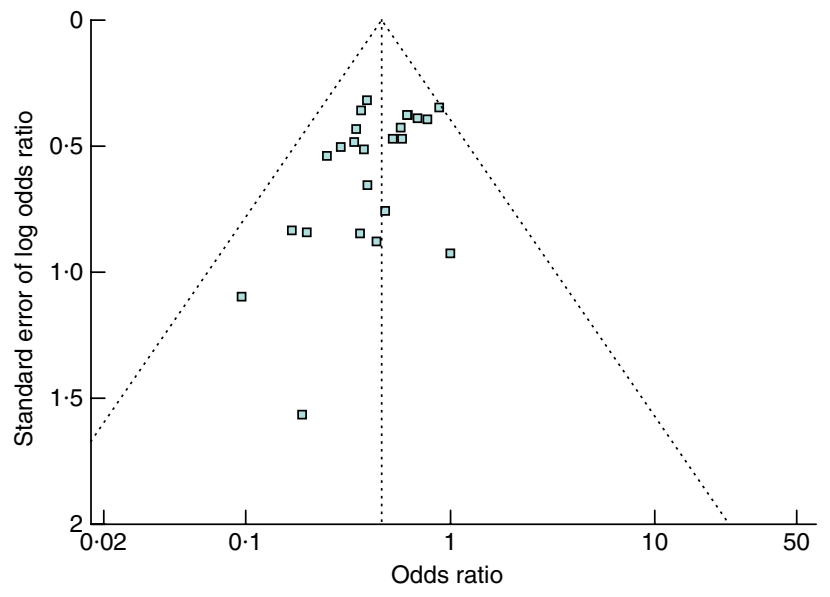

C Infections
The duration of preoperative nutritional support varied from 5 to 7 days. The most commonly administered preoperative quantity was $1000 \mathrm{ml} /$ day. Postoperative nutritional therapy was started within the first $24 \mathrm{~h}$ in all studies, and lasted from 3 days to more than 10 days. Postoperative IN was usually administered using nutritional catheters with increasing infusion rates up to $25 \mathrm{kcal}$ per $\mathrm{kg}$ per day $(800-2100 \mathrm{ml} /$ day) by the third day after surgery (Table 1$)$.

Data on preoperative nutritional status were provided in 13 studies. Malnutrition was considered as an inclusion criterion in two RCTs $\mathrm{s}^{26,28}$ and an exclusion criterion in two others ${ }^{7,32}$. In the remaining nine studies ${ }^{10,12-14,16,17,19,24,29}$ (1145 patients), the prevalence

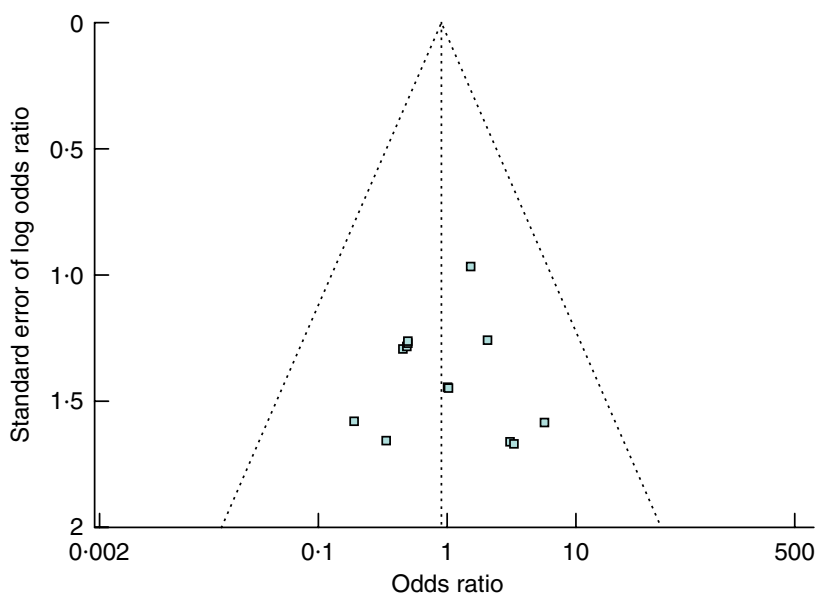

b Mortality

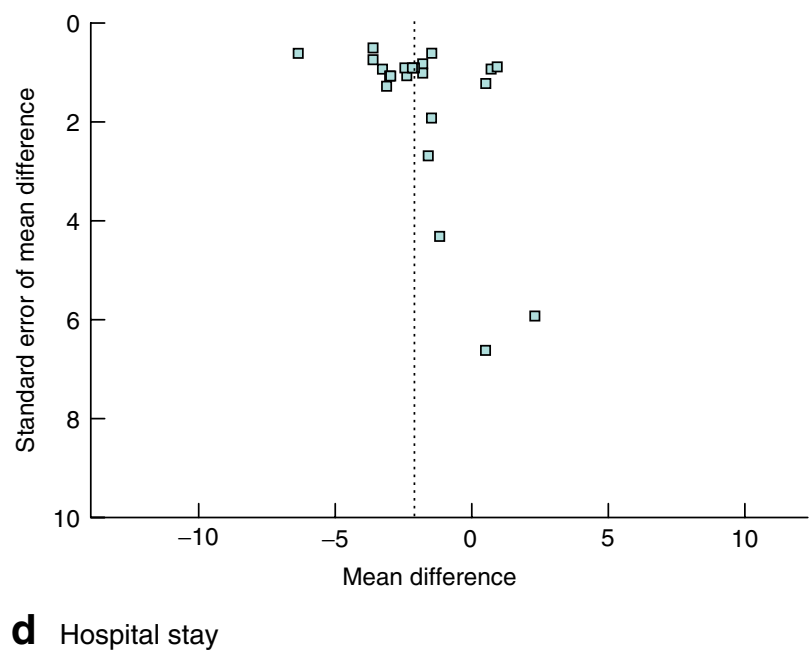

Fig. 2 Test of heterogeneity of selected randomized controlled trials on clinical impact of perioperative immunonutrition in major gastrointestinal surgery. Funnel plots were used to assess possible publication bias, based on overall pooled data for a overall complications, $\mathbf{b}$ mortality, $\mathbf{c}$ infections and $\mathbf{d}$ hospital stay 
of malnutrition ranged from 8 to 67 (median 26) per cent. There was no significant difference between study and control groups. Antibiotic prophylaxis was given routinely, whereas postoperative antibiotic treatment for $24 \mathrm{~h}$ was used selectively in only two trials ${ }^{13,29}$.

\section{Quality assessment and publication bias}

Study quality was heterogeneous (Table 2). Four studies fulfilled all five criteria of the Jadad score ${ }^{12,14,15,18}$, another study met four criteria ${ }^{16}$, seven studies had a Jadad score of $3^{2,7,10,13,17,19,28}$, and the remaining nine had a score of less than 3 . Only 11 of 21 studies provided analysis on an intention-to-treat-basis $7,10,17,24,25,27-31,33$. Withdrawals and dropouts were reported in 14 of 21 studies $^{2,7,10,12-19,26-28}$. Double-blinding and blinding prerequisites were the two most violated quality criteria.

Funnel plots for log OR (mean difference in the case of hospital stay) from the included studies were used to assess possible publication bias. There was no asymmetry

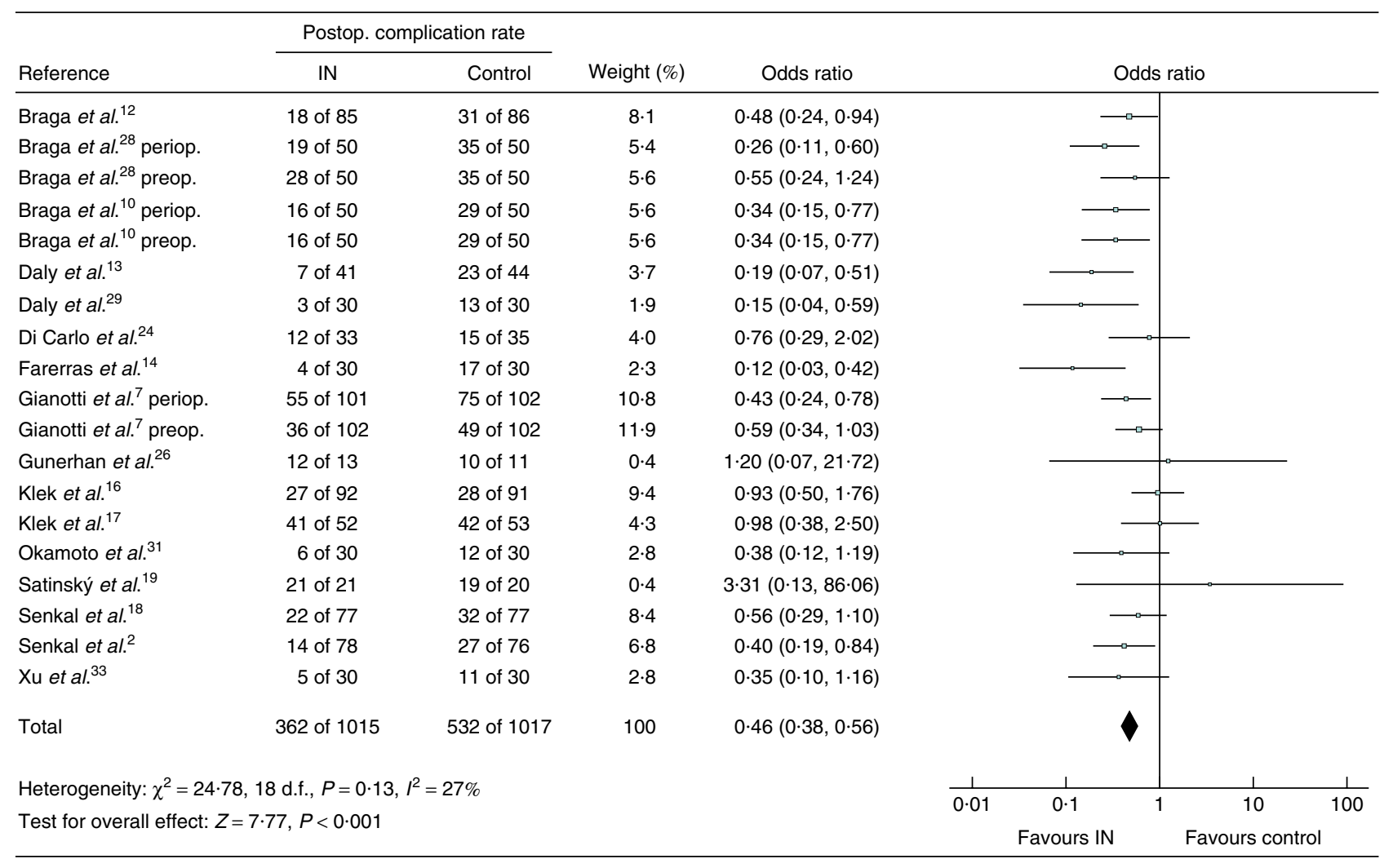

Fig. 3 Forest plot showing influence of perioperative immunonutrition (IN) on overall postoperative complication rates in patients undergoing major gastrointestinal surgery. Data across studies were pooled using a fixed-effects (inverse variance) model. Total numbers of individual complications are shown. Odds ratios are presented with 95 per cent confidence intervals

Table 3 Pooled data for high-quality studies only

\begin{tabular}{|c|c|c|c|}
\hline \multirow[b]{2}{*}{ Outcome measure } & \multicolumn{2}{|c|}{ Rate } & \multirow[b]{2}{*}{ Odds ratio } \\
\hline & IN & Control & \\
\hline Complications $^{2,7,10,12-19,28}$ & 338 of 956 & 495 of 957 & $0.46(0.38,0.57)$ \\
\hline Infections $\mathbf{S}^{2,7,10,12-19,28}$ & 177 of 956 & 306 of 957 & $0.47(0.38,0.59)$ \\
\hline Length of hospital stay ${ }^{2,7,10,12-18,28}$ (1837 patients) & - & - & $-2.26(-2.65,-1.88)^{\star}$ \\
\hline Mortality ${ }^{7,10,12-14,16-18,28}$ & 13 of 797 & 13 of 803 & $1.01(0.46,2.23)$ \\
\hline
\end{tabular}

Values in parentheses are 95 per cent confidence intervals. ${ }^{*}$ Mean difference. Only trials with a Jadad score of at least 3 were included. IN, immunonutrition. 
for postoperative infectious complications and mortality. Funnel plots for overall complications showed only minor asymmetry $\left(\chi^{2}=24.78,18\right.$ d.f., $I^{2}=27$ per cent $)$ and those for hospital stay revealed a major asymmetry $\left(\chi^{2}=104 \cdot 39\right.$, 20 d.f., $I^{2}=81$ per cent) (Fig. 2).

\section{Effect of immunonutrition on overall postoperative complications}

Of the 21 studies included in the meta-analysis, five $\mathrm{e}^{15,25,27,30,32}$ did not provide data on overall morbidity. Therefore, 16 studies (19 comparisons) comprising 2032 patients using different time schedules for IN were pooled to estimate the overall effect on postoperative morbidity $2,7,10,12-14,16-19,24,26,28,29,31,33$. An OR of $0.46(0.38$ to 0.56$)$ was found in favour of IN (Fig. 3). When studies of minor quality (Jadad score below 3 ) were excluded, the results remained essentially unchanged (Table 3).

Five $^{7,10,28,31,33}$ of six studies assessing preoperative application of IN favoured the use of IN, although a significance difference was found in only one ${ }^{10}$. Pooled results of all six studies ${ }^{7,10,26,28,31,33}$ favoured preoperative use of IN (OR $0.48,0.34$ to $0.69 ; \chi^{2}=2 \cdot 13, I^{2}=0$ per cent, $Z=3.99$ )

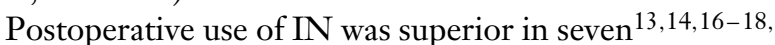
24,29 of eight studies $^{13,14,16-19,24,29}$, although in only three $e^{13,14,29}$ of these was the difference statistically significant. Pooled data were clearly advantageous for postoperative IN (OR $0.46,0.25$ to $0.84 ; \chi^{2}=19.21$, $I^{2}=64$ per cent, $Z=2.52$ ).

Pooled data from five studies ${ }^{2,7,10,12,28}$ combining preoperative and postoperative IN favoured IN with respect to postoperative complications (OR 0.39, 0.28 to $0.54 ; \chi^{2}=1.41, I^{2}=0$ per cent, $Z=5.79$ ).

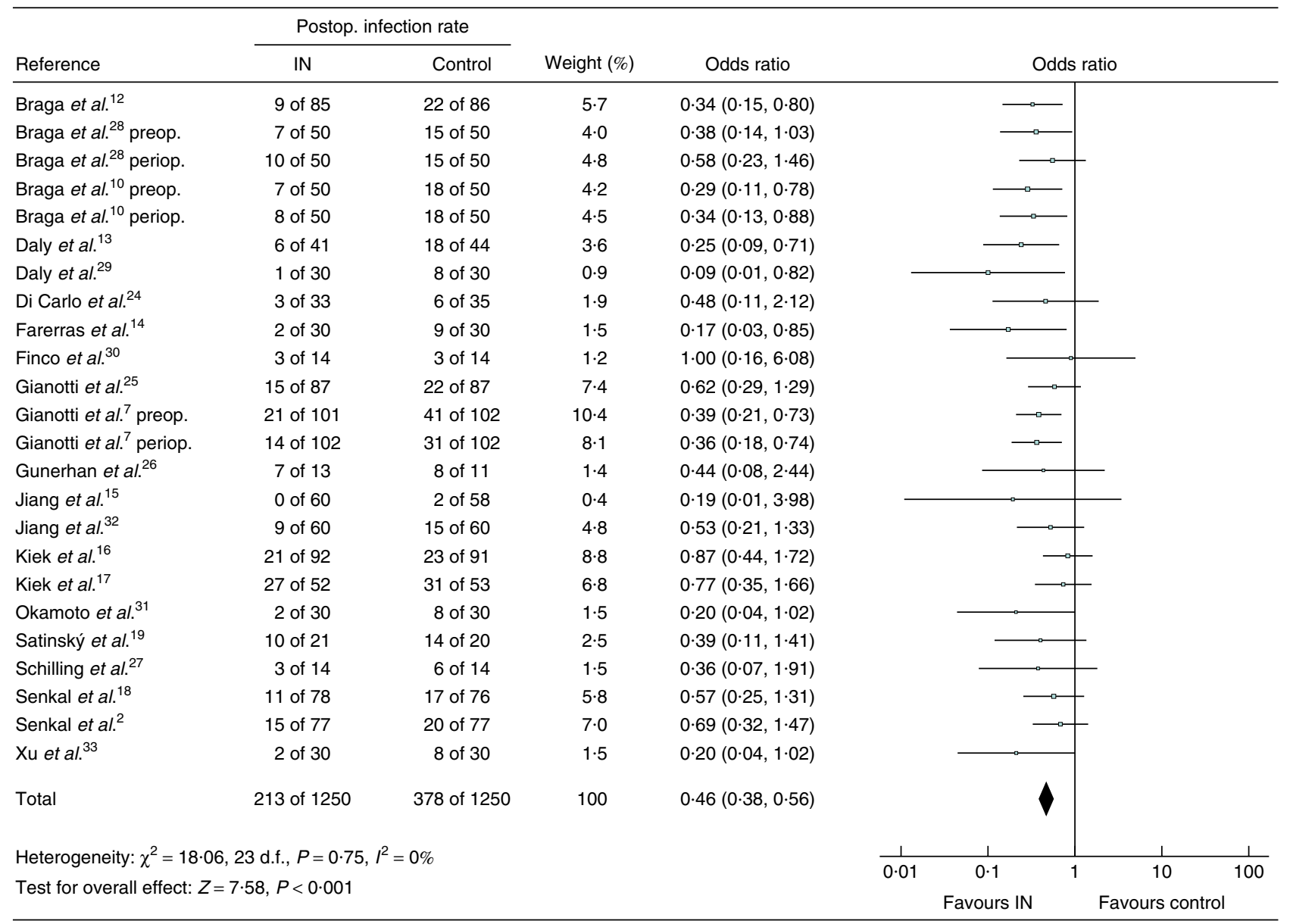

Fig. 4 Forest plot showing influence of perioperative immunonutrition (IN) on postoperative infection rates in patients undergoing major gastrointestinal surgery. Total numbers of individual infections are shown. Data across studies were pooled using a fixed-effects (inverse variance) model. Odds ratios are presented with 95 per cent confidence intervals 


\section{Effect of immunonutrition on postoperative infection}

All 21 studies provided data concerning infectious complications and could therefore be included in the final analysis. Pooled data for all three different time schedules were assessed, and preoperative, postoperative, and combined preoperative and postoperative regimens were also considered separately.

Pooled data from all studies assessing one of the three different treatment regimens favoured IN with respect to postoperative infections (OR $0.46,0.38$ to 0.56) (Fig. 4). Exclusion of studies of minor quality did not essentially change results (Table 3). Pooled data from studies evaluating preoperative application of IN favoured the treatment group (OR 0.36, 0.24 to 0.56; $\chi^{2}=2 \cdot 15, I^{2}=0$ per cent; $\left.Z=4.63\right)$. Studies assessing postoperative IN had ORs ranging from 0.09 to $0 \cdot 87$. Pooled data from these studies favoured postoperative IN with respect to postoperative infections (OR 0.53, 0.40 to $0.71 ; \chi^{2}=10.85 ; I^{2}=0$ per cent; $\left.Z=4.33\right)$. Studies of combined preoperative and postoperative use of IN showed a pooled OR of $0.41\left(0.28\right.$ to $0.58 ; \chi^{2}=2.22 ; I^{2}=0$ per cent; $Z=4.95)$.

\section{Effect of immunonutrition on length of hospital stay}

All except three studies ${ }^{14,19,32}$ provided data concerning length of hospital stay. Twenty-one comparisons including 2279 patients were pooled to estimate the length of hospital stay. The pooled mean difference was $-2.12(-2.97$ to -1.26 ) days in favour of IN (Fig. 5). Separate analyses of preoperative (mean difference $-2.42,-3.21$ to 1.63 ; $\chi^{2}=1.64, I^{2}=0$ per cent, $Z=5.97$ ), perioperative (mean difference $-1.63,-3.00$ to $-0.26 ; \chi^{2}=16.51, I^{2}=76$ per cent, $Z=2.33$ ) and postoperative (mean difference -2.05 , -3.77 to $-0.33 ; \chi^{2}=74.70, I^{2}=89$ per cent, $Z=2.34$ ) regimens favoured the use of IN to decrease hospital stay. The essence of these findings remained unchanged when only high-quality studies were considered (Table 3).

\begin{tabular}{|c|c|c|c|c|c|c|c|c|c|c|}
\hline \multirow{3}{*}{$\frac{\text { Reference }}{\text { Braga et al. }{ }^{12}}$} & \multicolumn{2}{|l|}{ IN } & \multicolumn{2}{|c|}{ Control } & \multirow{2}{*}{$\begin{array}{c}\text { Weight } \\
(\%)\end{array}$} & \multirow[b]{2}{*}{ Mean difference } & \multirow{2}{*}{\multicolumn{4}{|c|}{ Mean difference }} \\
\hline & \multirow{2}{*}{$\begin{array}{r}\text { Stay (days) } \\
11 \cdot 1(4 \cdot 4)\end{array}$} & \multirow{2}{*}{$\frac{n}{85}$} & \multirow{2}{*}{$\begin{array}{l}\text { Stay (days) } \\
12 \cdot 9(4 \cdot 6)\end{array}$} & \multirow{2}{*}{$\begin{array}{l}n \\
86\end{array}$} & & & & & & \\
\hline & & & & & $5 \cdot 9$ & $-1 \cdot 80(-3 \cdot 15,-0 \cdot 45)$ & & $\rightarrow-$ & & \\
\hline Braga et al. ${ }^{28}$ preop. & $12(3 \cdot 8)$ & 50 & $15 \cdot 3(4 \cdot 1)$ & 50 & $5 \cdot 7$ & $-3 \cdot 30(-4 \cdot 85,-1 \cdot 75)$ & & $\multimap$ & & \\
\hline Braga et al. ${ }^{28}$ postop. & $13 \cdot 2(3.5)$ & 50 & $15 \cdot 3(4 \cdot 1)$ & 50 & $5 \cdot 7$ & $-2 \cdot 10(-3.59,-0.61)$ & & $\neg-$ & & \\
\hline Braga et al. ${ }^{10}$ preop. & $9 \cdot 8(3 \cdot 1)$ & 50 & $12(4 \cdot 5)$ & 50 & $5 \cdot 7$ & $-2 \cdot 20(-3.71,-0.69)$ & & $\rightarrow$ & & \\
\hline Braga et al. ${ }^{10}$ postop. & $9 \cdot 5(2 \cdot 9)$ & 50 & $12(4 \cdot 5)$ & 50 & $5 \cdot 7$ & $-2.50(-3.98,-1.02)$ & & $\multimap-$ & & \\
\hline Daly et al. ${ }^{13}$ & $18 \cdot 8(11 \cdot 1)$ & 41 & $20 \cdot 4(9 \cdot 6)$ & 44 & $2 \cdot 4$ & $-1.60(-6.03,2 \cdot 83)$ & & & & \\
\hline Daly et al. ${ }^{29}$ & $16(0.9)$ & 30 & $22(2 \cdot 9)$ & 30 & $6 \cdot 2$ & $-6.00(-7.09,-4.91)$ & & $\rightarrow-$ & & \\
\hline Di Carlo et al..$^{24}$ & $16 \cdot 3(6 \cdot 2)$ & 33 & $17 \cdot 8(6 \cdot 9)$ & 35 & $3 \cdot 6$ & $-1.50(-4.61,1.61)$ & & & - & \\
\hline Finco et al. ${ }^{30}$ & $7 \cdot 7(2 \cdot 3)$ & 14 & $6 \cdot 8(1 \cdot 6)$ & 14 & $5 \cdot 8$ & $0.90(-0.57,2.37)$ & & & $\square$ & \\
\hline Gianotti et al. ${ }^{25}$ & $16 \cdot 1(6 \cdot 2)$ & 87 & $19 \cdot 2(7 \cdot 9)$ & 87 & 4.9 & $-3.10(-5.21,-0.99)$ & & $\longrightarrow-$ & & \\
\hline Gianotti et al. ${ }^{7}$ preop. & $12 \cdot 2(4 \cdot 1)$ & 101 & $14(7 \cdot 7)$ & 102 & $5 \cdot 5$ & $-1 \cdot 80(-3.49,-0 \cdot 11)$ & & & & \\
\hline Gianotti et al. ${ }^{7}$ postop. & $11 \cdot 6(4 \cdot 7)$ & 102 & $14(7 \cdot 7)$ & 102 & $5 \cdot 4$ & $-2.40(-4.15,-0.65)$ & & $\longrightarrow$ & & \\
\hline Gunerhan et al. $^{26}$ & $16 \cdot 5(14 \cdot 8)$ & 13 & $14 \cdot 2(9 \cdot 1)$ & 11 & 0.7 & $2 \cdot 30(-7.38,11.98)$ & & & & \\
\hline Jiang et al. ${ }^{15}$ & $13(2 \cdot 5)$ & 60 & $14 \cdot 5(3)$ & 58 & $6 \cdot 3$ & $-1.50(-2.50,-0.50)$ & & $\neg-$ & & \\
\hline Klek et al. ${ }^{16}$ & $12 \cdot 9(8)$ & 92 & $12 \cdot 4(5 \cdot 9)$ & 91 & $5 \cdot 0$ & $0.50(-1.54,2.54)$ & & & - & \\
\hline Klek et al. ${ }^{17}$ & $13 \cdot 1(4 \cdot 1)$ & 52 & $12 \cdot 4(3 \cdot 9)$ & 53 & $5 \cdot 7$ & $0.70(-0.83,2.23)$ & & & $\square$ & \\
\hline Okamoto et al. ${ }^{31}$ & $23 \cdot 8(16 \cdot 6)$ & 30 & $25(10 \cdot 6)$ & 30 & $1 \cdot 2$ & $-1.20(-8.25,5.85)$ & & & & \\
\hline Schilling et al. ${ }^{27}$ & $14 \cdot 5(8)$ & 14 & 14(19) & 14 & 0.6 & $0.50(-10.30,11.30)$ & & & & \\
\hline Senkal et al..$^{18}$ & $27(2 \cdot 3)$ & 77 & $30 \cdot 6(3 \cdot 1)$ & 77 & 6.5 & $-3.60(-4 \cdot 46,-2 \cdot 74)$ & & $\rightarrow$ & & \\
\hline Senkal et al. ${ }^{2}$ & $22 \cdot 2(4 \cdot 1)$ & 78 & $25 \cdot 8(3 \cdot 8)$ & 76 & $6 \cdot 1$ & $-3 \cdot 60(-4 \cdot 85,-2 \cdot 35)$ & & $\rightarrow$ & & \\
\hline Xu et al..$^{33}$ & $9(3.2)$ & 30 & $12(3 \cdot 7)$ & 30 & $5 \cdot 4$ & $-3 \cdot 00(-4 \cdot 75,-1 \cdot 25)$ & & $\longrightarrow$ & & \\
\hline Total & & 1139 & & 1140 & 100 & $-2 \cdot 12(-2 \cdot 97,-1 \cdot 26)$ & & & & \\
\hline \multicolumn{7}{|c|}{ Heterogeneity: $\tau^{2}=2 \cdot 74, \chi^{2}=104.39,20$ d.f., $P<0.001, I^{2}=81 \%$} & 1 & 1 & $\perp$ & L \\
\hline \multirow{2}{*}{\multicolumn{7}{|c|}{ Test for overall effect: $Z=4.85, P<0.001$}} & -10 & -5 & 0 & 10 \\
\hline & & & & & & & \multicolumn{4}{|c|}{ Favours IN Favours control } \\
\hline
\end{tabular}

Fig. 5 Forest plot showing influence of perioperative immunonutrition (IN) on length of hospital stay of patients undergoing major gastrointestinal surgery. Data across studies were pooled using a fixed-effects (inverse variance) model. *Values are mean(s.d.). Mean differences are presented with 95 per cent confidence intervals 


\section{Influence of immunonutrition on mortality rates}

Fifteen studies (1999 patients) $)^{7,10,12-14,16-19,24,25,27-30}$ reporting on mortality rates were included in the analysis. Administration of IN had no influence on overall pooled mortality rates (OR $0.90,0.46$ to 1.76 ). Restriction to high-quality studies confirmed no beneficial effect of IN on mortality rates (Table 3).

\section{Tolerance and costs of immunonutrition}

Precise data on tolerance with enteral feeding were reported in six trials ${ }^{7,12,14,17,24,30}$. Tolerance was assessed as a dichotomized variable: the presence or absence of 'any intolerance event (vomiting, nausea, displacement of nasogastric tube, abdominal cramping, bloating)'. The pooled data showed comparable results for IN, given before, after or both before and after surgery, and control groups (OR 1.15, 0.50 to 2.65).

Economic issues were addressed in three studies (462 patients $)^{2,15,18}$. In cost-effectiveness analyses, the global cost per patient for IN versus control groups was reported in two studies ${ }^{2,15}$ and total costs in one ${ }^{18}$. The differences in mean costs were $€ 1426, € 2281$ and $€ 23248$ respectively, in favour of $\mathrm{IN}^{2,15,18}$. This corresponded with mean savings of 52,13 and 18 per cent respectively.

\section{Discussion}

This systematic review of 21 RCTs containing 2730 patients evaluated the impact of IN on postoperative morbidity and mortality in patients undergoing planned major gastrointestinal surgery. The most important finding was that IN decreased overall complication rates and, in particular, the rate of infectious complications, either with preoperative, postoperative or combined preoperative and postoperative use. Moreover, IN shortened hospital stay. However, postoperative mortality rates were comparable between IN and control groups.

Meta-analyses are inherently limited by the quality of the original data, and their selection and analysis. The present evaluation aimed to minimize selection bias (for example by having no restriction with regard to language or nutritional formula) and duplication of data by using a thorough selection process. Analysis and data presentation adhere to the recently published PRISMA guidelines ${ }^{23}$. However, where significant heterogeneity of available trials was demonstrated, expressed as an $I^{2}$ value of more than 60 per cent, cautious interpretation of results is needed. Furthermore, only 12 of 21 included RCTs were considered as high quality, defined as having a Jadad score of at least $3^{22}$. Of specific concern, withdrawals were reported in only 14 of 21 studies.

Until the advent of immunomodulatory agents almost 25 years ago, nutritional support was traditionally considered as adjunctive care to provide sufficient caloric intake to malnourished patients undergoing major surgery (for example cancer and trauma surgery) or patients with critical illness. Arginine, glutamine, $n-3 \mathrm{FA}$ and RNA, the most common components of IN, are used in various combinations and doses. These novel nutritional supplements have effects on cell-mediated immune function, release of acute-phase proteins, the post-traumatic inflammatory cascade, and release of hormones such as insulin ${ }^{10,11}$. Despite being 'biologicals', they act in a pharmacological manner, and can be therefore considered as real pharmaconutrients. Although their therapeutic effects are well documented in experimental settings, assessment in daily clinical practice is more difficult. It has been increasingly recognized that pharmaconutrients impact differently on patients undergoing elective surgery and those with critical illness ${ }^{4,34}$. Heyland and colleagues ${ }^{35}$ found in their meta-analysis that patients undergoing elective surgery had fewer postoperative infections when treated with IN. However, IN failed to improve postoperative outcome (infection rate and mortality) in critically ill patients.

More than 30 randomized controlled trials aimed at assessing the clinical significance of IN in surgical patients have been performed during the past two decades. A close look at the results reveals wide disparity that often impedes firm conclusions. Several systematic reviews and meta-analyses have been carried out in recent years to resolve some of the controversies. In surgical patients, IN reduced postoperative infection rates and decreased length of hospital stay, but mortality rates remained unchanged $4,11,20,21,34,36-38$. Preoperative treatment for $5-7$ days with $500-1000 \mathrm{ml}$ of an enteral nutritional formula containing arginine, $n-3 \mathrm{FA}$ and RNA proved to be most beneficial ${ }^{21}$. Waitzberg and colleagues ${ }^{21}$ conducted an industry-driven meta-analysis in different surgical patient groups (abdominal, cardiac, head and neck $)^{21}$. The study selection focused on one nutritional formula (IMPACT ${ }^{\circledR}$; Nestlé, Vevey, Switzerland) and the significant heterogeneity of data was not further considered. Of note, some of the included studies compared enteral IN with total parenteral nutrition, which is known to be less effective and therefore represents an inadequate control group ${ }^{39-43}$. Zheng and co-workers ${ }^{11}$ analysed 13 RCTs containing 1269 patients. This study was restricted to oncological surgery and publications in English. Moreover, both of these meta-analyses considered the number of patients with complications and not the 
number of individual complications. As cost analysis relies on the cost of each complication, and considering that the aim of IN is to reduce complications, it was thought more representative to include each single complication separately. Thus, numbers differ from those in previous analyses. The present meta-analysis deals with the largest number of RCTs and patients, and also includes the most recently published trials on the use of perioperative IN.

The mechanisms underlying the effect of IN and the most efficacious mode of delivery remain controversial. The timing of supplementation has been debated. Three studies have found no difference when comparing preoperative and perioperative IN regimens ${ }^{7,10,28}$. Another study compared perioperative administration of IN with postoperative IN alone ${ }^{44}$. A significant decrease in postoperative complications was seen in the perioperative IN group compared with the postoperative IN group. As oxidative stress leading to mitochondrial dysfunction may become irreversible within $6-24 \mathrm{~h}$, it seems the sooner IN is applied, the more beneficial for the patient ${ }^{45}$.

The quantity of IN administered is also a matter of debate. A dose of $25 \mathrm{kcal}$ per $\mathrm{kg}$ per day is about the standard ${ }^{20}$. The amount of IN used in five studies was clearly below this goal ${ }^{2,14,27,30,31}$. Another topic that has been widely debated is the composition of IN diets. Pharmaconutrients are often administered in combination and the benefits of individual components are difficult to assess. Some advocate that supplementation with fish oil alone could decrease complication rates ${ }^{46}$. Gianotti and colleagues ${ }^{47}$ have shown recently that perioperative glutamine does not affect outcome in well nourished patients with gastrointestinal cancer, whereas others ${ }^{48}$ have found a significant difference in favour of glutamine supplementation. Interestingly, the four studies included in present meta-analysis that used an IN composition lacking RNA did not show a significant reduction in the rate of infectious complications ${ }^{16,17,19,32}$.

Indications for the use of IN are also subject to discussion. Owing to heterogeneity among studies included in this meta-analysis, no conclusions can be drawn about whether or not malnourished patients benefit most from IN. The American guidelines define malnutrition as involuntary weight loss of 5 per cent or 10 per cent of usual bodyweight in 1 or 6 months respectively ${ }^{49}$. The European Society of Parenteral and Enteral Nutrition screening guidelines recommend use of the Nutritional Risk Score (NRS), which integrates nutritional status, disease severity and age to identify patients at nutritional risk $^{50,51}$. Patients with a NRS of at least 3 are prone to developing more complications while in hospital and are likely to benefit from nutritional support ${ }^{3,50-52}$. None of the included RCTs based their indication for perioperative nutrition on screening using the NRS. An ongoing doubleblinded randomized trial (registration no. NCT00512213; http://www.clinicaltrials.gov) is evaluating the clinical benefit of IN in patients undergoing gastrointestinal surgery who are at nutritional risk.

The present meta-analysis did not show any significant effect of IN on mortality. Data on mortality were available for 1999 patients, but only 36 deaths were reported. Because of the very low mortality rate, the present pooled sample size is underpowered to show small differences in mortality rate.

Length of hospital stay is rather a 'soft' criterion, and discharge from hospital is often driven more by the individual healthcare system and hospital reimbursement system than by 'hard' medical indications. Therefore, the quality of results is impaired, as shown by the related asymmetry in the funnel plot, and caution is needed in interpretation of these results. Nevertheless, it seems logical that a reduction in (infectious) complications entails a reduced hospital stay, as shown by others ${ }^{1}$.

Tolerance of enteral feeding with IN was similar to that with standard formula. This is not surprising, as most of the nutrition-related adverse events were caused by the use of feeding tubes that were used equally in groups being compared ${ }^{7,12}$. The higher direct costs of IN were outweighed by the lower overall complication rates and shorter hospital stay. Diederich and colleagues ${ }^{53}$ performed a cost analysis based on two included studies ${ }^{2,18}$. They found a net cost-effectiveness favouring IN, taking into account complication rate, cost of nutrition formula and health insurance reimbursement.

Perioperative use of IN can be recommended for all patients undergoing major abdominal surgery.

\section{Acknowledgements}

Y.C. and M.H. share first authorship of this article. The authors thank Marco Braga for critically reviewing his publications for duplicate data and patient overlap. Yabo Wang and Fabienne Gaugas provided translations from papers written originally in Chinese and Czech respectively. The authors declare no conflict of interest.

\section{References}

1 Bozzetti F, Gianotti L, Braga M, Di Carlo V, Mariani L. Postoperative complications in gastrointestinal cancer patients: the joint role of the nutritional status and the nutritional support. Clin Nutr 2007; 26: 698-709.

2 Senkal M, Zumtobel V, Bauer KH, Marpe B, Wolfram G, Frei A et al. Outcome and cost-effectiveness of perioperative 
enteral immunonutrition in patients undergoing elective upper gastrointestinal tract surgery: a prospective randomized study. Arch Surg 1999; 134: 1309-1316.

3 Sorensen J, Kondrup J, Prokopowicz J, Schiesser M, Krähenbühl L, Meier R et al.; EuroOOPS study group. EuroOOPS: an international, multicentre study to implement nutritional risk screening and evaluate clinical outcome. Clin Nutr 2008; 27: 340-349.

4 Jones NE, Heyland DK. Pharmaconutrition: a new emerging paradigm. Curr Opin Gastroenterol 2008; 24: 215-222.

5 Marik PE, Zaloga GP. Immunonutrition in critically ill patients: a systematic review and analysis of the literature. Intensive Care Med 2008; 34: 1980-1990.

6 Schwegler I, von Holzen A, Gutzwiller JP, Schlumpf R, Mühlebach S, Stanga Z. Nutritional risk is a clinical predictor of postoperative mortality and morbidity in surgery for colorectal cancer. Br 7 Surg 97: 92-97.

7 Gianotti L, Braga M, Nespoli L, Radaelli G, Beneduce A, Di Carlo V. A randomized controlled trial of preoperative oral supplementation with a specialized diet in patients with gastrointestinal cancer. Gastroenterology 2002; 122: $1763-1770$.

8 Weimann A, Braga M, Harsanyi L, Laviano A, Ljungqvist O, Soeters $\mathrm{P}$ et al. ESPEN Guidelines on Enteral Nutrition: surgery including organ transplantation. Clin Nutr 2006; 25 : 224-244.

9 Stratton RJ, Elia M. Who benefits from nutritional support: what is the evidence? Eur 7 Gastroenterol Hepatol 2007; 19: $353-358$.

10 Braga M, Gianotti L, Vignali A, Carlo VD. Preoperative oral arginine and $n-3$ fatty acid supplementation improves the immunometabolic host response and outcome after colorectal resection for cancer. Surgery 2002; 132: 805-814.

11 Zheng Y, Li F, Qi B, Luo B, Sun H, Liu S et al. Application of perioperative immunonutrition for gastrointestinal surgery: a meta-analysis of randomized controlled trials. Asia Pac 7 Clin Nutr 2007; 16(Suppl 1): 253-257.

12 Braga M, Gianotti L, Radaelli G, Vignali A, Mari G, Gentilini $\mathrm{O}$ et al. Perioperative immunonutrition in patients undergoing cancer surgery: results of a randomized double-blind phase 3 trial. Arch Surg 1999; 134: 428-433.

13 Daly JM, Lieberman MD, Goldfine J, Shou J, Weintraub F, Rosato EF et al. Enteral nutrition with supplemental arginine, RNA, and omega-3 fatty acids in patients after operation: immunologic, metabolic, and clinical outcome. Surgery 1992; 112: 56-67.

14 Farreras N, Artigas V, Cardona D, Rius X, Trias M, González JA. Effect of early postoperative enteral immunonutrition on wound healing in patients undergoing surgery for gastric cancer. Clin Nutr 2005; 24: 55-65.

15 Jiang ZM, Gu ZY, Chen FL, Wang XR, Li ZJ, Xu Y et al. (The role of immune enhanced enteral nutrition on plasma amino acid, gut permeability and clinical outcome (a randomized, double blind, controlled, multi-center clinical trial with 120 cases).) Zhongguo Yi Xue Ke Xue Yuan Xue Bao 2001; 23: 515-518.
16 Klek S, Kulig J, Sierzega M, Szczepanek K, Szybiński P, Scislo L et al. Standard and immunomodulating enteral nutrition in patients after extended gastrointestinal surgery - a prospective, randomized, controlled clinical trial. Clin Nutr 2008; 27: 504-512.

17 Klek S, Kulig J, Sierzega M, Szybinski P, Szczepanek K, Kubisz A et al. The impact of immunostimulating nutrition on infectious complications after upper gastrointestinal surgery: a prospective, randomized, clinical trial. Ann Surg 2008; 248: 212-220.

18 Senkal M, Mumme A, Eickhoff U, Geier B, Spath G, Wulfert $\mathrm{D}$ et al. Early postoperative enteral immunonutrition: clinical outcome and cost-comparison analysis in surgical patients. Crit Care Med 1997; 25: 1489-1496.

19 Satinský I, Mitták M, Foltys A, Kretek J, Dostalík J. (Comparison of various types of artificial nutrition on postoperative complications after major surgery.) Rozhl Chir 2005; 84: 134-141.

20 Akbarshahi H, Andersson B, Nordén M, Andersson R. Perioperative nutrition in elective gastrointestinal surgery - potential for improvement? Dig Surg 2008; 25: $165-174$.

21 Waitzberg DL, Saito H, Plank LD, Jamieson GG, Jagannath P, Hwang TL et al. Postsurgical infections are reduced with specialized nutrition support. World 7 Surg 2006; 30: 1592-1604.

22 Jadad AR, Moore RA, Carroll D, Jenkinson C, Reynolds DJ, Gavaghan DJ et al. Assessing the quality of reports of randomized clinical trials: is blinding necessary? Control Clin Trials 1996; 17: 1-12.

23 Moher D, Liberati A, Tetzlaff J, Altman DG; PRISMA Group. Preferred reporting items for systematic reviews and meta-analyses: the PRISMA statement. BM7 2009; 339: b2535.

24 Di Carlo V, Gianotti L, Balzano G, Zerbi A, Braga M. Complications of pancreatic surgery and the role of perioperative nutrition. Dig Surg 1999; 16: 320-326.

25 Gianotti L, Braga M, Vignali A, Balzano G, Zerbi A, Bisagni $\mathrm{P}$ et al. Effect of route of delivery and formulation of postoperative nutritional support in patients undergoing major operations for malignant neoplasms. Arch Surg 1997; 132: $1222-1229$.

26 Gunerhan Y, Koksal N, Sahin UY, Uzun MA, Ekşioglu-Demiralp E. Effect of preoperative immunonutrition and other nutrition models on cellular immune parameters. World 7 Gastroenterol 2009; 15 : $467-472$

27 Schilling J, Vranjes N, Fierz W, Joller H, Gyurech D, Ludwig E et al. Clinical outcome and immunology of postoperative arginine, omega-3 fatty acids, and nucleotide-enriched enteral feeding: a randomized prospective comparison with standard enteral and low calorie/low fat i.v. solutions. Nutrition 1996; 12: 423-429.

28 Braga M, Gianotti L, Nespoli L, Radaelli G, Di Carlo V. Nutritional approach in malnourished surgical patients: a 
prospective randomized study. Arch Surg 2002; 137: 174-180.

29 Daly JM, Weintraub FN, Shou J, Rosato EF, Lucia M. Enteral nutrition during multimodality therapy in upper gastrointestinal cancer patients. Ann Surg 1995; 221 : 327-338.

30 Finco C, Magnanini P, Sarzo G, Vecchiato M, Luongo B, Savastano $\mathrm{S}$ et al. Prospective randomized study on perioperative enteral immunonutrition in laparoscopic colorectal surgery. Surg Endosc 2007; 21: 1175-1179.

31 Okamoto Y, Okano K, Izuishi K, Usuki H, Wakabayashi H, Suzuki Y. Attenuation of the systemic inflammatory response and infectious complications after gastrectomy with preoperative oral arginine and omega- 3 fatty acids supplemented immunonutrition. World 7 Surg 2009; 33: $1815-1821$

32 Jiang XH, Li N, Zhu WM, Wu GH, Quan ZW, Li JS. Effects of postoperative immune-enhancing enteral nutrition on the immune system, inflammatory responses, and clinical outcome. Chin Med 7 (Engl) 2004; 117: 835-839.

$33 \mathrm{Xu}$ J, Zhong Y, Jing D, Wu Z. Preoperative enteral immunonutrition improves postoperative outcome in patients with gastrointestinal cancer. World 7 Surg 2006; 30: 1284-1289.

34 Calder PC. Immunonutrition in surgical and critically ill patients. Br 7 Nutr 2007; 98(Suppl 1): S133-S139.

35 Heyland DK, Novak F, Drover JW, Jain M, Su X, Suchner U. Should immunonutrition become routine in critically ill patients? A systematic review of the evidence. 7AMA 2001; 286: 944-953.

36 Kudsk KA. Immunonutrition in surgery and critical care. Annu Rev Nutr 2006; 26: 463-479.

37 McCowen KC, Bistrian BR. Immunonutrition: problematic or problem solving? Am 7 Clin Nutr 2003; 77: 764-770.

38 Senesse P, Assenat E, Schneider S, Chargari C, Magné N, Azria D et al. Nutritional support during oncologic treatment of patients with gastrointestinal cancer: who could benefit? Cancer Treat Rev 2008; 34: 568-575.

39 Bozzetti F, Braga M, Gianotti L, Gavazzi C, Mariani L. Postoperative enteral versus parenteral nutrition in malnourished patients with gastrointestinal cancer: a randomised multicentre trial. Lancet 2001; 358: 1487-1492.

40 Koretz RL, Avenell A, Lipman TO, Braunschweig CL, Milne AC. Does enteral nutrition affect clinical outcome? A systematic review of the randomized trials. Am $\mathcal{F}$ Gastroenterol 2007; 102: 412-429.

41 Braunschweig CL, Levy P, Sheean PM, Wang X. Enteral compared with parenteral nutrition: a meta-analysis. $A m \mathcal{F}$ Clin Nutr 2001; 74: 534-542.

42 Peter JV, Moran JL, Phillips-Hughes J. A metaanalysis of treatment outcomes of early enteral versus early parenteral nutrition in hospitalized patients. Crit Care Med 2005; 33: $213-220$.

43 Simpson F, Doig GS. Parenteral vs. enteral nutrition in the critically ill patient: a meta-analysis of trials using the intention to treat principle. Intensive Care Med 2005; 31: $12-23$.

44 Giger U, Buchler M, Farhadi J, Berger D, Husler J, Schneider $\mathrm{H}$ et al. Preoperative immunonutrition suppresses perioperative inflammatory response in patients with major abdominal surgery - a randomized controlled pilot study. Ann Surg Oncol 2007; 14: 2798-2806.

45 Levy RJ, Deutschman CS. Cytochrome c oxidase dysfunction in sepsis. Critical Care Med 2007; 35(Suppl): S468-S475.

46 Kenler AS, Swails WS, Driscoll DF, DeMichele SJ, Daley B, Babineau TJ et al. Early enteral feeding in postsurgical cancer patients. Fish oil structured lipid-based polymeric formula versus a standard polymeric formula. Ann Surg 1996; 223 : 316-333.

47 Gianotti L, Braga M, Biffi R, Bozzetti F, Mariani L; GlutamItaly Research Group of the Italian Society of Parenteral, and Enteral Nutrition. Perioperative intravenous glutamine supplementation in major abdominal surgery for cancer: a randomized multicenter trial. Ann Surg 2009; 250: 684-690.

48 Oguz M, Kerem M, Bedirli A, Mentes BB, Sakrak O, Salman B et al. L-Alanine-L-glutamine supplementation improves the outcome after colorectal surgery for cancer. Colorectal Dis 2007; 9: 515-520.

49 ASPEN Board of Directors and the Clinical Guidelines Task Force. Guidelines for the use of parenteral and enteral nutrition in adult and pediatric patients. FPEN $\mathcal{F}$ Parenter Enteral Nutr 2002; 26(Suppl): 1SA-138SA.

50 Kondrup J, Allison SP, Elia M, Vellas B, Plauth M; Educational and Clinical Practice Committee, European Society of Parenteral and Enteral Nutrition (ESPEN). ESPEN guidelines for nutrition screening 2002. Clin Nutr 2003; 22: 415-421.

51 Kondrup J, Rasmussen HH, Hamberg O, Stanga Z; Ad Hoc ESPEN Working Group. Nutritional risk screening (NRS 2002): a new method based on an analysis of controlled clinical trials. Clin Nutr 2003; 22: 321-336.

52 Schiesser M, Müller S, Kirchhoff P, Breitenstein S, Schäfer M, Clavien PA. Assessment of a novel screening score for nutritional risk in predicting complications in gastro-intestinal surgery. Clin Nutr 2008; 27: 565-570.

53 Diederich KC, Schmid A, Schneider H, Kemen M. Immunonutrition and postoperative complications under G-DRGs: a comparison of complication costs with their actual G-DRG-based reimbursement rates of patients undergoing major gastrointestinal surgery with and without the perioperative use of immunonutrition. Aktuelle Ernabrungsmedizin 2005; 30: 247-254. 


\section{Commentary}

\section{Immunonutrition in gastrointestinal surgery (Br J Surg 2011; 98; 37-48)}

This is a well conducted review and meta-analysis of the literature regarding the clinical effects of perioperative immunonutrition (IN) in patients undergoing elective gastrointestinal surgery. The authors clearly show the benefits of IN in decreasing the number of complications and length of postoperative stay, and emphasize that such treatment is cost effective despite the higher cost of these formulations containing $n-3$ fatty acids compared with standard ones.

Because the results from randomized controlled trials, systematic reviews and meta-analyses are accepted worldwide as the best scientific evidence to support clinical decisions, the logical consequence from these studies should be that IN becomes, without further delay, an essential part of the armamentarium of the gastrointestinal surgeon. There are, however, some drawbacks in such a policy, the factors being 'time' and 'alternatives'.

\section{Time}

The authors' conclusions are supported by a technically perfect analysis on such a large number of patients that no-one could argue against these robust data. Nevertheless, it has to be acknowledged that the first recommendations on the perioperative use of $n-3$ fatty acids from a consensus of experts date back to $2001^{1}$. In subsequent years other national and international scientific societies have replicated these recommendations. Hence, meta-analyses often stipulate certain concepts that are already known to the experts in that area. It is worth noting that, although several randomized trials on IN have been published in surgical journals, most previous meta-analyses appeared in nutritional journals. This seems odd and it may appear that optimal perioperative nutritional support is a specialist issue rather than a general one that should be of interest to all surgeons.

\section{Alternatives}

The success of IN should be weighed against the current and complex enhanced recovery after surgery (ERAS) programmes. Recent randomized trials and meta-analyses on this topic have also emphasized that the ERAS approach in similar groups of patients reduces the number of complications and shortens postoperative hospital stay ${ }^{2}$. Finally, it should be noted that a single surgeon may choose to use IN, whereas a policy of ERAS requires a multidisciplinary and institutional decision. Future studies are needed to compare the two approaches to try to merge them, and to expand the use of IN to patients undergoing emergency surgery.

F. Bozzetti

Faculty of Medicine, University of Milan, Milan, Italy

(e-mail:dottfb@tin.it)

DOI: $10.1002 /$ bjs. 7272

\section{References}

1 Consensus recommendations from the US summit on immune-enhancing enteral therapy 7 PEN 7 Parenter Enteral Nutr 2001; 25(Suppl): S61-S63.

2 Hendry PO, Hausel J, Nygren J, Lassen K, Dejong CH, Ljungqvist O et al.; Enhanced Recovery After Surgery Study Group. Determinants of outcome after colorectal resection within an enhanced recovery programme. Br F Surg 2009; 96: 197-205. 